\title{
Improved numerical weather predictions by using optimised urban model parameter values and satellite derived tree heights
}

\author{
I. Dharssi $^{\text {a }}{ }^{\text {P. Steinle }}{ }^{\mathrm{a}}$ and J. Fernon ${ }^{\mathrm{a}}$ \\ ${ }^{a}$ Bureau of Meteorology, Melbourne, Victoria, Australia \\ Email: i.dharssi@bom.gov.au
}

\begin{abstract}
About $90 \%$ of the Australian population lives in urban areas yet numerical weather prediction (NWP) systems poorly represent urban areas. The Australian Community Climate and Earth System Simulator (ACCESS) uses a simple urban model with only three parameters; heat capacity, albedo and aerodynamic roughness length (Best, 2005). The urban model parameters are set fixed to the same values at all urban areas, worldwide. This urban model was developed in the United Kingdom and consequently the default urban parameter values are unlikely to be appropriate for Australia. A previous study (Best et al., 2006) has used observations of surface fluxes from Mexico City and Vancouver to evaluate this urban model and concluded that much better estimates of the sensible heat flux are provided when a significantly smaller value for the urban heat capacity parameter is used. This urban model contains no information about the three dimensional morphology of the buildings and consequently the urban heat capacity parameter is not well defined and cannot be measured.

The ACCESS NWP system simply assumes that over most of Australia, including urban areas, trees are 28 metres tall. ACCESS NWP assumes that the heat capacity of trees increases with tree height and follows a power law while the aerodynamic roughness length increases linearly with tree height (Essery et al., 2001). A halving of model tree heights causes the heat capacity of model trees to reduce by a factor of almost six.

In this study we use revised urban model parameter values that are more appropriate for Australia and a global dataset of forest canopy height derived from satellite LIDAR measurements to improve the ACCESS NWP system. Experiments show that the use of the new urban model parameters and tree heights results in significantly improved forecasts of air temperature at a height of 2 metres above the surface (screen level).
\end{abstract}

Keywords: Urban, weather, heat capacity, Albedo, roughness length 
I Dharssi. Improved weather predictions using optimised urban parameters and satellite derived tree heights

\section{ACCESS NWP MODEL}

The operational Numerical Weather Prediction (NWP) system employed by the Bureau of Meteorology is part of the Australian Community Climate and Earth System Simulator (ACCESS; Puri et al., 2013). Different configurations of ACCESS are used across many time and space scales; from very high resolution fire modelling (spatial resolution of $\simeq 0.5 \mathrm{~km}$ ) to lower resolution climate prediction (spatial resolution of $\simeq 100 \mathrm{~km}$ ), see figure 1 . The high resolution model configurations forecast weather a few hours to a few days ahead while the low resolution climate configurations predict changes over decades to centuries. The atmosphere and land surface are fully coupled in all configurations.

\subsection{Urban scheme}

The ACCESS NWP system uses the Met Office Surface Exchange Scheme version 2 (MOSES2) land surface model (Essery et al., 2001). Surface heterogeneity, within each model surface grid square, is represented by the use of 5 vegetation tiles and 4 non-vegetation tiles, including an urban tile. The urban tile is represented using a very simple and computationally cheap urban model (Urban canopy scheme; Best, 2005; Best et al., 2006). Due to it's simplicity, the urban canopy scheme cannot represent the detailed differences between cities. In particular, the urban scheme contains no information about the three-dimensional morphology of buildings. The urban scheme partitions the available energy at the surface into sensible and latent heat fluxes and heat storage within the urban canopy; the urban canopy is then radiatively coupled to the underlying soil, see figure 2. The flux of moisture from the urban tile is limited to the evaporation of available water lying on the urban surface (and not from soil moisture). The urban scheme uses only three parameters; heat capacity (default value $2.8 \times 10^{5} \mathrm{Jm}^{-2} \mathrm{~K}^{-1}$; note the unusual units), albedo (default value 0.18 ) and aerodynamic roughness length (default value $1.0 \mathrm{~m}$ ). These parameters are set fixed to the same values at all urban areas, worldwide. Unfortunately, the urban heat capacity parameter is not well defined and cannot be measured, (Best et al., 2006). Consequently, Best et al. (2006) suggest that this parameter can be calibrated to improve NWP skill. Anthropogenic heat sources are neglected by the urban scheme. Evaluation of the urban scheme against surface energy balance observations shows significant discrepancies in the partitioning of turbulent and storage heat fluxes between predicted and observed values. Of the turbulent fluxes, latent heat fluxes are under-predicted by about one order of magnitude. Comparison with observations shows the urban scheme to be particularly sensitive to changes in the urban heat capacity parameter. Model performance was found to be optimal with model heat capacity values smaller than the default values. Best et al. (2006) suggest that the urban scheme is too simple and improvements may be obtained by increasing the complexity of the model.

\subsection{Tree Heights}

Until recently, ACCESS NWP specified vegetation canopy height using IGBP land cover data (e.g. see table 1 of Cox et al., 1999). Consequently, the ACCESS NWP system unrealistically assumed that over most of Australia, including urban areas, trees are 28 metres tall. MOSES2 assumes that the heat capacity of trees increases with tree height and follows a power law while the aerodynamic roughness length increases linearly with tree height. Therefore, tree height can have a significant impact on forecasts of temperature and wind speed. This work uses a global dataset of canopy height derived from space-borne light detection and ranging (LIDAR; Simard et al., 2011) to specify tree heights for the Australia domain. Figure 4 shows a comparison of the old and new tree heights for the ACCESS Sydney domain NWP model. The new tree heights are much shorter in urban areas.

\section{SENSITIVITY EXPERIMENTS}

Verification studies using screen level observations showed that ACCESS NWP temperature forecasts had too small a diurnal range and a slow wind bias. Moreover, the verification indicated that the forecasts errors were particularly large over urban areas such as Sydney. Sensitivity experiments showed that soil moisture and temperature were not the cause of the large errors over urban areas. However, experiments showed significant sensitivity to the urban canopy model parameters and model tree heights. The experiments showed the urban heat capacity parameter to be particularly important for temperature forecasts. Reducing the value of this parameter by a factor of 2.8 significantly improved temperature forecasts. Initially, short experiments covering a few days were run to examine the effect of individual changes to the model. Longer trials covering one month were performed using new urban parameter values of; heat capacity $\left(1.0 \times 10^{5} \mathrm{Jm}^{-2} \mathrm{~K}^{-1}\right)$, albedo $(0.10)$ and aerodynamic roughness length $(0.6 \mathrm{~m})$ together with model tree heights derived from space-borne LIDAR (see figure 5). Tables 1 and 2 show the root mean square difference (RMSD) between observations and forecasts for 
I Dharssi. Improved weather predictions using optimised urban parameters and satellite derived tree heights

the July 2013 and January 2014 trials. The RMSD values show that the new urban parameters and tree heights significantly improve forecasts of both screen temperature and $10 \mathrm{~m}$ wind speeds. The biggest improvements to temperature forecasts occur at night. For the sub-tropical Brisbane and Sydney model domains the temperature forecasts show the greatest improvements during the winter trial (July 2013). For the mid-latitude Victoria and Tasmania (VicTas) domain model the temperature forecasts show the greatest improvements during the summer trial (January 2014). The Adelaide domain model shows little sensitivity to the model changes while the Perth domain model shows a mixed but generally small response. The greater sensitivity to the model changes in the Brisbane, Sydney and VicTas domains is expected since these models contain large cities and significant tree cover. While the Adelaide and Perth domain models contain smaller cities and less tree cover. The greater sensitivity of the mid-latitude VicTas model during summer is expected since Melbourne has more clear days and fewer cloudy days in summer than winter. While Conversely, Brisbane and Sydney have far more clear days and fewer cloudy days in winter than in summer (see table 3).

\section{OPERATIONAL IMPLEMENTATION}

The new urban parameters and tree heights were implemented during July 2014 in the ACCESS NWP City models that run daily in near real-time for operational weather forecasting.

\section{CONCLUSions AND Future Work}

This work shows that the ACCESS NWP system is significantly sensitive to the parameterisation of urban areas and vegetation properties. This work has used a realistic data-set of tree heights based on space-borne LIDAR data. A simple tuning strategy has been used to find urban model parameters that provide better weather forecast. The current ACCESS NWP urban model is very simple and therefore the urban model parameters are not well defined and must be tuned to give adequate results. In conclusion, the ACCESS NWP system requires a much better, more realistic, physically based urban model to better serve the Australian community. Over the next decade, it is highly likely that the spatial resolution of the ACCESS NWP City models will increase to about $100 \mathrm{~m}$ and the requirement for a better, more realistic urban model will be even greater.

\section{REFERENCES}

Best, M., 2005: Representing urban areas within operational numerical weather prediction models. BoundaryLayer Meteorology, 114, 91-109, doi:10.1007/s10546-004-4834-5.

URL http://dx.doi.org/10.1007/s10546-004-4834-5

Best, M., C. Grimmond, and M. Villani, 2006: Evaluation of the Urban Tile in MOSES using Surface Energy Balance Observations. Boundary-Layer Meteorology, 118, 503-525, doi:10.1007/s 10546-005-9025-5. URL http://dx.doi.org/10.1007/s10546-005-9025-5

Cox, P. M., R. A. Betts, C. B. Bunton, R. L. H. Essery, P. R. Rowntree, and J. Smith, 1999: The impact of new land surface physics on the GCM simulation of climate and climate sensitivity. Climate Dynamics, $\mathbf{1 5}$, 183-203, doi:10.1007/s003820050276.

URL http://dx.doi.org/10.1007/s003820050276

Essery, R., M. Best, and P. Cox, 2001: Moses 2.2 technical documentation. Hadley Centre technical note 30, Met Office, Exeter, UK.

Loveland, T. R., B. C. Reed, J. F. Brown, D. O. Ohlen, Z. Zhu, L. Yang, and J. W. Merchant, 2000: Development of a global land cover characteristics database and IGBP DISCover from $1 \mathrm{~km} \mathrm{AVHRR} \mathrm{data.}$ International Journal of Remote Sensing, 21, 1303-1330, doi:10.1080/014311600210191. URL http://dx.doi.org/10.1080/014311600210191

Puri, K., G. Dietachmayer, P. Steinle, M. Dix, L. Rikus, L. Logan, M. Naughton, C. Tingwell, Y. Xiao, V. Barras, et al., 2013: Implementation of the initial ACCESS Numerical Weather Prediction system. Aust. Meteorol. Oceanogr. J, 63, 265-284.

Simard, M., N. Pinto, J. B. Fisher, and A. Baccini, 2011: Mapping forest canopy height globally with spaceborne lidar. Journal of Geophysical Research: Biogeosciences, 116, doi:10.1029/2011JG001708, g04021. URL http: / /dx.doi.org/10.1029/2011JG001708 
I Dharssi. Improved weather predictions using optimised urban parameters and satellite derived tree heights

Table 1. Root mean square difference (RMSD) between observations and forecasts for July 2013. The Control experiment uses the default urban parameters and old tree heights. The Test experiment uses the new urban parameters and space-borne LIDAR based tree heights. Smaller RMSD values are better.

\begin{tabular}{l|ccc|cc} 
Model Domains & \multicolumn{3}{|c|}{ Screen Temperature $(K)$} & \multicolumn{2}{c}{$10 \mathrm{~m}$ Wind Speed $(\mathrm{m} / \mathrm{s})$} \\
& Control & Test & Improvement & Control & Test \\
\hline \hline Brisbane & 1.92 & 1.67 & $13 \%$ & 1.66 & 1.64 \\
Sydney & 2.09 & 1.87 & $11 \%$ & 1.98 & 1.93 \\
Victoria Tasmania & 1.80 & 1.75 & $3 \%$ & 2.12 & 2.04 \\
Adelaide & 1.60 & 1.57 & $2 \%$ & 1.75 & 1.67 \\
Perth & 1.70 & 1.58 & $7 \%$ & 1.84 & 1.79
\end{tabular}

Table 2. Root mean square difference between observations and forecasts for January 2014. The Control experiment uses the default urban parameters and old tree heights. The Test experiment uses the new urban parameters and space-borne LIDAR based tree heights.

\begin{tabular}{l|ccc|cc}
\multirow{2}{*}{ Model Domains } & \multicolumn{3}{|c|}{ Screen Temperature $(K)$} & \multicolumn{2}{c}{$10 \mathrm{~m}$ Wind Speed $(\mathrm{m} / \mathrm{s})$} \\
& Control & Test & Improvement & Control & Test \\
\hline \hline Brisbane & 1.64 & 1.63 & $1 \%$ & 1.90 & 1.79 \\
Sydney & 1.98 & 1.82 & $8 \%$ & 2.03 & 1.93 \\
Victoria Tasmania & 2.13 & 1.98 & $7 \%$ & 2.09 & 2.00 \\
Adelaide & 2.07 & 2.04 & $1 \%$ & 1.93 & 1.84 \\
Perth & 1.78 & 1.82 & $-2 \%$ & 1.77 & 1.83
\end{tabular}

Table 3. Monthly mean number of clear days during January and July. A clear day is recorded when the mean of the 9 am and $3 \mathrm{pm}$ cloud observations is less than or equal to 2 oktas (eights). Source: http://www.bom.gov.au/climate/data/index.shtml?bookmark=200 .

\begin{tabular}{l|cc} 
Cities (Station Number) & \multicolumn{2}{|c}{ Clear Days } \\
& January & July \\
\hline \hline Brisbane (040223) & 4.7 & 15.3 \\
Sydney (066062) & 6.8 & 12.0 \\
Melbourne (086071) & 6.1 & 2.6
\end{tabular}


I Dharssi. Improved weather predictions using optimised urban parameters and satellite derived tree heights

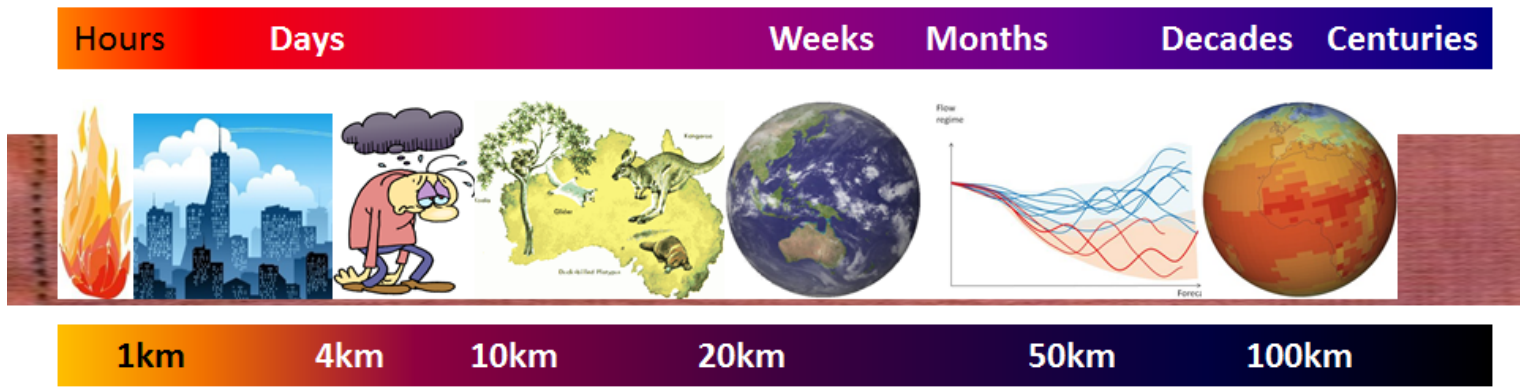

Figure 1. Seamless modelling of weather and climate by the Australian Community Climate and Earth System Simulator.

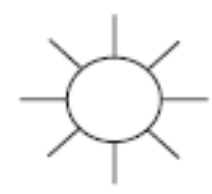

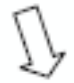

K*

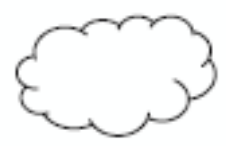

13

$\mathbf{L}$

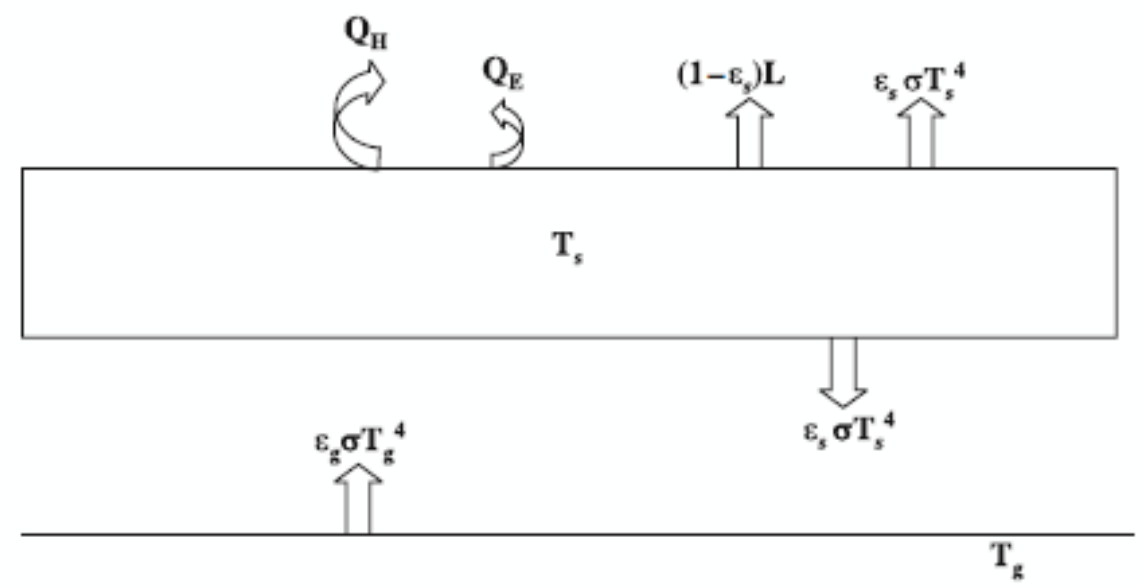

Figure 2. Surface energy balance in the ACCESS urban canopy model (from Best et al. (2006)). 
I Dharssi. Improved weather predictions using optimised urban parameters and satellite derived tree heights

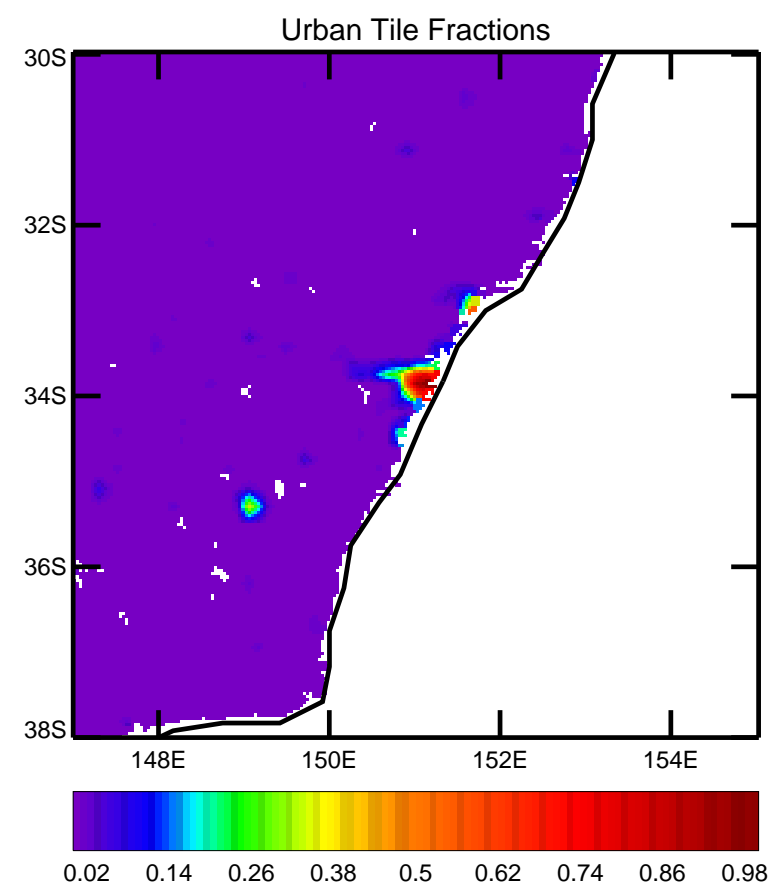

Figure 3. Urban tile fractions used by the ACCESS Sydney domain NWP model that covers much of New South Wales. ACCESS uses the $1 \mathrm{~km}$ resolution International Geosphere Biosphere Project (IGBP) land cover data (Loveland et al., 2000) which is derived from remotely sensed Normalised Difference Vegetation Index (NDVI) composites.

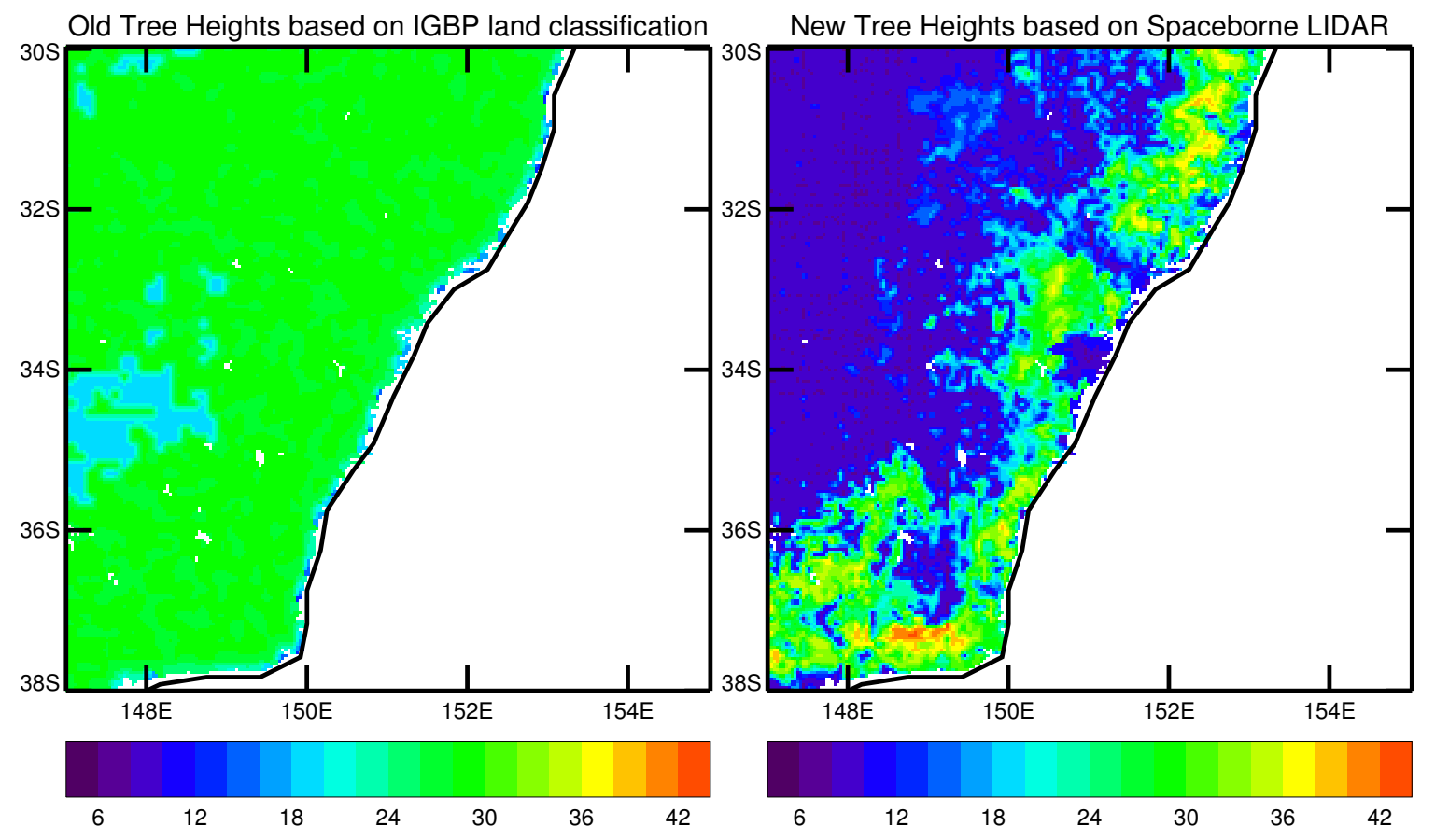

Figure 4. Tree heights used by the ACCESS Sydney domain NWP model $(m)$. The left (right) panel shows the old (new) tree heights based on IGBP land classification (space-borne LIDAR). 


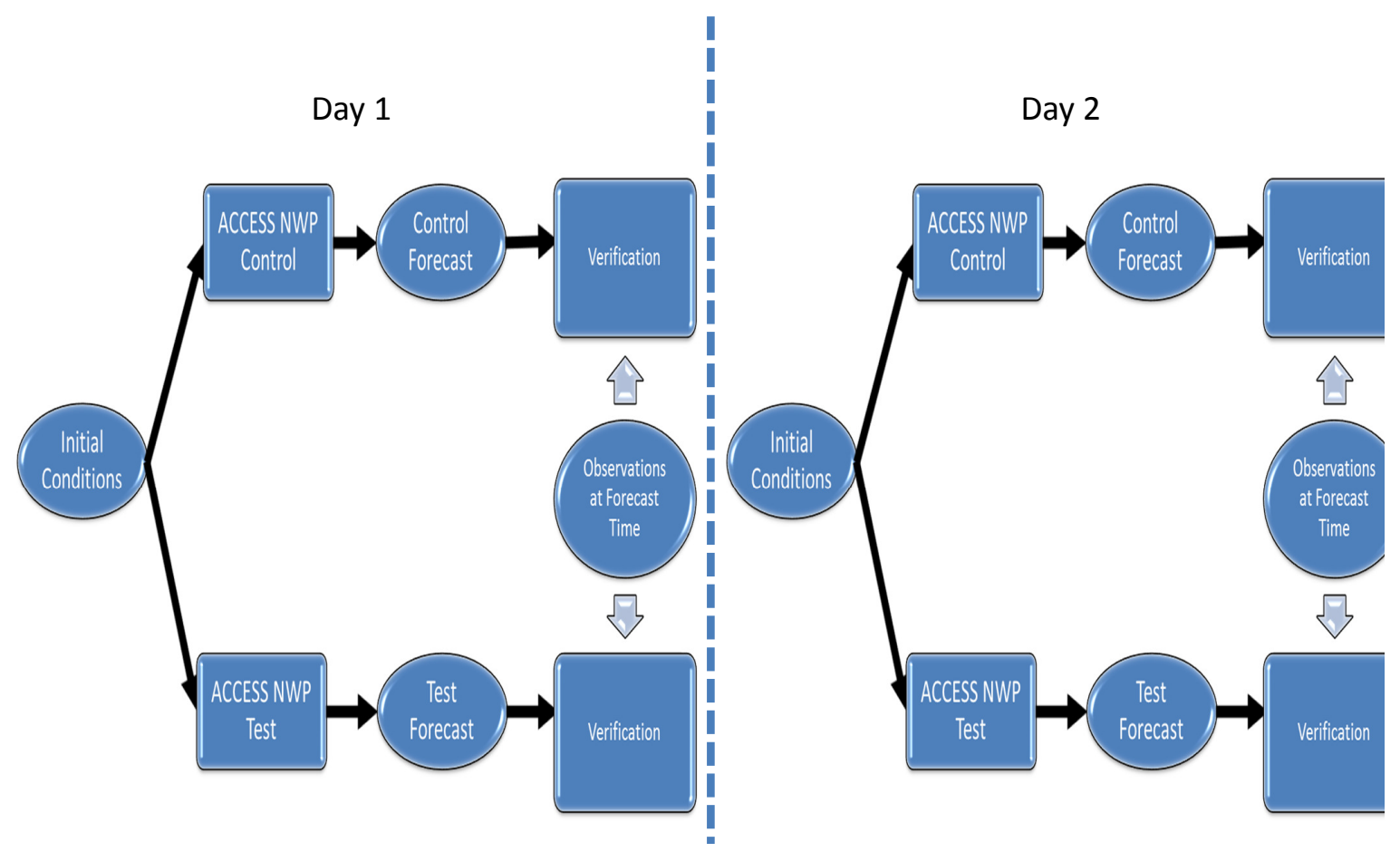

Figure 5. Schematic describing the one month long NWP trials performed to test the sensitivity of the ACCESS NWP system to model urban parameters and tree heights. The Control run uses the ACCESS NWP system with the default urban parameters and tree heights while the Test run uses the ACCESS NWP system with the revised urban parameters and tree heights. Otherwise, both the Control and Test runs are identical and use the same initial conditions (e.g. gridded fields of temperature, wind and humidity at the start of the forecast). Both the Control and Test runs produce gridded weather forecasts at regular intervals for 36 hours from the start of the forecast. The Control and Test forecasts are produced daily starting at 00 Greenwich Mean Time. The Control and Test forecasts are compared to temperature and wind observations valid at the forecast time and the RMSD between forecasts and observations is calculated. The model urban parameters and tree heights are time invariant and set to fixed values at the very start of the trial. 